\title{
AHBR
}

REVISTA DE ANTROPOLOGÍA IBEROAMERICANA

ESTIMADO LECTORIA:

GRACIAS POR DESCARGAR ESTE ARTÍCULO. EL TEXTO QUE ESTÁ A PUNTO DE CONSULTAR ES DE ACCESO LIBRE Y GRATUITO GRACIAS AL TRABAJO Y LA COLABORACIÓN DESINTERESADA DE UN AMPLIO COLECTIVO DE PROFESIONALES.

USTED PUEDE AYUDARNOS A INCREMENTAR LA CALIDAD Y A MANTENER LA LIBRE DIFUSIÓN DE LOS CONTENIDOS DE ESTA REVISTA A TRAVÉS DE SU AFILIACIÓN A LA ASOCIACIÓN AIBR:

\author{
http://www.aibr.org/antropologia/aibr/socios.php
}

La afiliación a AIBR tiene un coste mínimo al año, y le proporcionará las siguientes ventajas y privilegios:

1. Recibir en su domicilio la revista impresa, en Europa y América (tres números anuales), así como todas las novedades relativas al funcionamiento de la asociación.

2. Recibir en su domicilio, a precio especial o de forma gratuita, cuantas publicaciones adicionales edite la asociación.

3. Derecho a voto en las asambleas de socios, así como a presentarse como candidato a la elección de su Junta Directiva.

4. Recibir el boletín de socios (tres números anuales), así como la información económica relativa a cuentas anuales de la asociación.

5. Beneficiarse de las reducciones de precio en congresos, cursos, libros y todos aquellos convenios a los que a nivel corporativo AIBR llegue con otras entidades. En este momento, existen los siguientes acuerdos:

o Reducción de un $20 \%$ en el precio de todos los libros publicados por la editorial MELUSINA.

o Reducción de un $20 \%$ en el precio de todos los libros publicados por la editorial SEPHA.

o Reducción de un 30\% en el precio de todos los libros publicados por la editorial GRAN VÍA.

o Derecho a cuota reducida en los congresos trianuales de la FAAEE (España) y a los bianuales de la Sociedad Española de Antropología Aplicada.

6. Promoción gratuita, tanto a través de la revista electrónica como de la revista impresa, de aquellas publicaciones de las que sea autor y que estén registradas con ISBN. La difusión se realiza entre más de 5.600 antropólogos suscritos a la revista.

7. Cuenta de correo electrónico ilimitada de la forma socio@aibr.org, para consultar a través de webmail o cualquier programa externo.

8. Espacio para web personal de la forma http://www.aibr.org/(directorio)/(nombre) y cuenta propia de ftp.

9. Acceso con clave a todos los documentos de la Intranet de socios de AIBR, incluida la consulta a artículos en proceso de evaluación de la revista AIBR.

10. Promoción gratuita a través de la revista (banner rotativo y reseña) de aquellos eventos, congresos, conferencias o cursos en los que usted forme parte del comité organizador.

11. Opción a formar parte como evaluador de los artículos recibidos por la revista.

IMPORTE DE LA CUOTA ANUAL: Hasta diciembre de 2008, la cuota única anual es de 32 (euros). Su validez es de un año a partir del pago de la cuota. Por favor, revise la actualización de cuotas en nuestra web.

PARA HACERSE SOCIO DE AIBR, POR FAVOR, CONSULTE LA SIGUIENTE DIRECCIÓN:

http://www.aibr.org/antropologia/aibr/socios.php 


\title{
"VERGÜENZA DE VIVIR DONDE VIVO": IDEAS
}

PARA UNA RE-CONCEPTUALIZACIÓN DE LA

SEGREGACIÓN RESIDENCIAL SOCIOECONÓMICA ${ }^{1}$

\section{Susana Cortés}

\author{
Universidad de Chile
}

\begin{abstract}
Resumen
Santiago, capital de Chile, se caracteriza por un patrón distributivo de segregación residencial socioeconómica en gran escala, sin espacios urbanos de contacto entre los habitantes de diferentes estratos sociales. Sin embargo, en las últimas dos décadas se ha observado casos en que la escala geográfica de segregación residencial se ha reducido, acortándose la distancia entre familias de muy bajos y altos ingresos en comunas periféricas, originalmente ocupadas por campamentos y habitantes de escasos recursos, hoy vecinos de condominios cerrados. ¿Constituye este fenómeno una nueva tendencia distributiva o son sólo casos aislados?; ¿qué efectos socioespaciales tiene para estas comunas, sus habitantes y la ciudad, a corto y largo plazo?; ¿puede la reducción de escala de segregación residencial generar instancias de interacción e integración social? Este artículo reflexiona en torno a estas preguntas sobre el caso particular de la comuna de Peñalolén. Analiza los efectos negativos del fenómeno así como ideas sobre por qué la interacción e integración social no son consecuencias naturales de la cercanía física en el actual contexto social y económico de Chile y del mundo globalizado. Finalmente, en base a la teoría de la lógica del espacio de los flujos de Manuel Castells, y su aplicación al caso estudiado, se reflexiona sobre las definiciones de segregación residencial y las metodologías para su estudio, proponiendo la necesidad de una re-conceptualización que incluya nuevas técnicas, enfatizando la metodología cualitativa que la Antropología puede aportar.
\end{abstract}

\section{Palabras clave}

Segregación residencial socioeconómica, escala geográfica de segregación, lógicas espaciales, barrio cerrado.

\section{"I AM ASHAMED OF LIVING WHERE I LIVE": IDEAS FOR RECONCEPTUALIZING SOCIOECONOMICAL RESIDENTIAL SEGREGATION}

\begin{abstract}
Santiago, Capital of Chile, is characterized by a large scale pattern of socioeconomic residential segregation. There are very few spaces where the inhabitants of different social strata interact. However, in the last two decades there have been examples in which the scale of residential segregation has been reduced, with a narrowed distance between families of very low and high income in peripheral districts. While originally these peripheral areas were slums occupied by
\end{abstract}

\footnotetext{
${ }^{1}$ Este artículo ha sido escrito en el contexto de mi tesis de grado. Las referencias a entrevistas o conversaciones con habitantes de la comuna de Peñalolén corresponden a entrevistas exploratorias realizadas con este propósito. La tesis revisa los efectos de la SRS en escala reducida en niños y niñas del condominio El Olmo y villa El Parral.
} 
low income dwellers, today the two communities are neighbors in private condos. Does this new phenomena constitute a wide tendency or is it something found in isolated cases? What sociospatial effect does this have for these communities, their inhabitants and the city as a whole in the short and long term? Can the reduction of residential segregation generate moments of social interaction and integration?

This paper examines these questions, through the particular case of the Peñalolén borough. The paper outlines the possible negative effects of this phenomenon as well as examines why interaction and social integration are not natural consequences of the close proximity in the actual social and economic context of Chile. Finally, starting from Manuel Castells' theory of the logical flow of space and its application in the case study we review the idea of residential segregation and the methodologies for its study, proposing that there is a need to re-consider this term and to consider new methods for studying it, which emphasize the qualitative methodology that Anthropology can contribute.

\section{Keywords}

Socioeconomic residential segregation, geographical segregation scale, spatial logic, gated communities.

Recibido: 26 de Marzo de 2008

Aceptado: 15 de Julio de 2008

\section{Introducción}

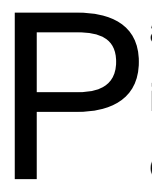

arece ser un hecho común que siendo adulto se recuerden sucesos de la infancia y se los comprenda de manera distinta que en su momento, a la luz de vivencias, prejuicios y conceptos que hemos adquirido posteriormente. Por ejemplo, recuerdo que cuando tenía unos 12 años (año 1993-1994) un día fue una compañera de colegio a almorzar a mi casa. A esa edad no me interesaba saber dónde vivían las personas, no era algo que se me ocurriera preguntar, y de todos modos no conocía la ciudad como para ubicar las direcciones. Pero durante el almuerzo mi mamá le preguntó a mi compañera dónde vivía, y ella respondió: "es que me da vergüenza decirlo, lo que pasa es que vivo en Peñalolén, y ahí hay puros rascas $^{2} \ldots$ pero yo vivo en el Parque Tobalaba". En ese entonces no me hizo mucho sentido su respuesta.

Hoy, bajo los conceptos y teorías referentes a la segregación residencial socioeconómica, este recuerdo ha cobrado sentido, y me ha resultado muy ilustrativo del fenómeno al que este artículo se refiere: la segregación residencial socioeconómica (SRS en adelante), y la reducción de su escala geográfica en algunas zonas de Santiago, Chile.

\footnotetext{
${ }^{2}$ Rascas: expresión usada para referirse negativamente a personas, conductas u objetos. En el caso de las personas, hace referencia a un grupo social "inferior", asociado a falta de educación y/o valores. En este mismo sentido se entiende tratándose de conductas rascas, como propias de éstas personas. En el caso de los objetos, indica mala calidad.
} 
1. Tendencia distributiva general de Santiago: segregación residencial en gran escala

Santiago, capital de Chile se caracteriza, al igual que muchas otras ciudades latinoamericanas, por manifestar y reforzar sus desigualdades sociales y económicas a través de la distribución residencial de sus habitantes, según un patrón de segregación residencial socioeconómica (SRS) de gran escala. Esto significa, por una parte, que la ciudad se encuentra segmentada en áreas internamente homogéneas en términos socioeconómicos, y por otra, que las áreas más pobres y más ricas están alejadas geográficamente unas de otras, conformando grandes y bien demarcados sectores ocupados por familias de un mismo grupo socioeconómico. En el caso particular de Santiago, se observa la formación de un "cono", el cono oriente, que se extiende desde el centro de la ciudad hacia el nororiente, hasta el sector precordillerano, conteniendo el denominado "barrio alto", donde se concentran los habitantes de más altos ingresos, y algunos pequeños sectores de bajos ingresos que quedaron infiltrados desde épocas anteriores a la dictadura de Augusto Pinochet. En su mayoría estos grupos o asentamientos precarios fueron erradicados hacia la periferia sur y poniente de Santiago, donde se concentran las grandes zonas de pobreza. Así, el espacio urbano está fragmentado entre estratos socioeconómicos diferentes que se ubican en territorios bien definidos sin que coexistan distintos estratos en un mismo espacio. En modalidad de gran escala, la segregación se observa con la ciudad entera como marco de referencia. Se anula la posibilidad de encuentro entre los grupos. No sólo de un encuentro profundo, sino en el sentido del más simple cruce de caras, de pisar la misma vereda o compartir el nombre de la calle e incluso comuna en la dirección personal.

Existe una división administrativa del territorio en 34 comunas (antiguamente 17, las cuales fueron subdivididas doblando su número a raíz de de las reformas de la dictadura militar), siendo posible identificar cada una con un destino o grupo socioeconómico relativamente homogéneo. Es decir, en muchos casos puede decirse que las áreas homogéneas de las que se ha hablado coinciden con límites comunales, o con un grupo de comunas vecinas que constituyen un área mayor. Esta condición se ve reforzada por el sistema financiero impuesto por la descentralización administrativa: cada comuna se financia principalmente con sus propios ingresos, que provienen por ejemplo del pago de permisos de circulación (automóviles), construcción (inmobiliarias), 
etcétera, por parte de sus habitantes y de las empresas. Así las comunas más pobres siguen siendo siempre las más pobres, ya que sus habitantes pagan menos permisos de circulación, más baratos, y la actividad inmobiliaria es escasa. Sus escuelas, centros médicos e infraestructura pública deben desarrollarse con el escaso presupuesto municipal. Mientras tanto, las comunas con habitantes de mayores ingresos cuentan con más recursos para implementar infraestructura y servicios públicos, los cuales además tienen una demanda menor, ya que la mayoría de sus habitantes acceden a la oferta privada en educación, salud y recreación.

Esta asociación entre división administrativa y grupos socioeconómicos permite a los habitantes de las distintas zonas de la ciudad identificar y discriminar automáticamente a las personas según su comuna de residencia. Mencionaré un ejemplo significativo. Una colega antropóloga realizó su tesis de grado en una escuela básica de La Granja, comuna fuertemente asociada por la prensa a la delincuencia y el narcotráfico. En general tuvo una buena relación con los niños, hasta el último día, en que le preguntaron dónde vivía ella. Bastó que escucharan el nombre de la comuna, Providencia, para que le llovieran todo tipo de proyectiles (desde papeles a escupos) e insultos anónimos mientras intentaba terminar con la clase que el director del establecimiento le había pedido realizar a cambio de permitirle hacer ahí su investigación. La -quizás no tan- prejuiciosa reacción de los alumnos es parte de lo mismo que la llevó a escoger a los estudiantes de esa escuela y esa comuna, sin antes conocerlos, para llevar a cabo un estudio sobre imágenes de la delincuencia que tienen los niños, los cuales por el solo hecho de vivir ahí, seguramente tendrían un padre, tío o al menos un vecino narcotraficante, supuso mi colega.

Siendo este el patrón de distribución residencial que caracteriza a Santiago, el cual genera una asociación directa entre comunas y grupos socioeconómicos, y recordando la anécdota que da inicio a este escrito, es posible preguntarse qué hacía mi compañera de colegio viviendo en Peñalolén, una comuna que, al menos desde su perspectiva, no se correspondía con el nivel socioeconómico de su familia, y por qué se excusaba y validaba especificando el recinto en que vivía, el "Parque Tobalaba". 


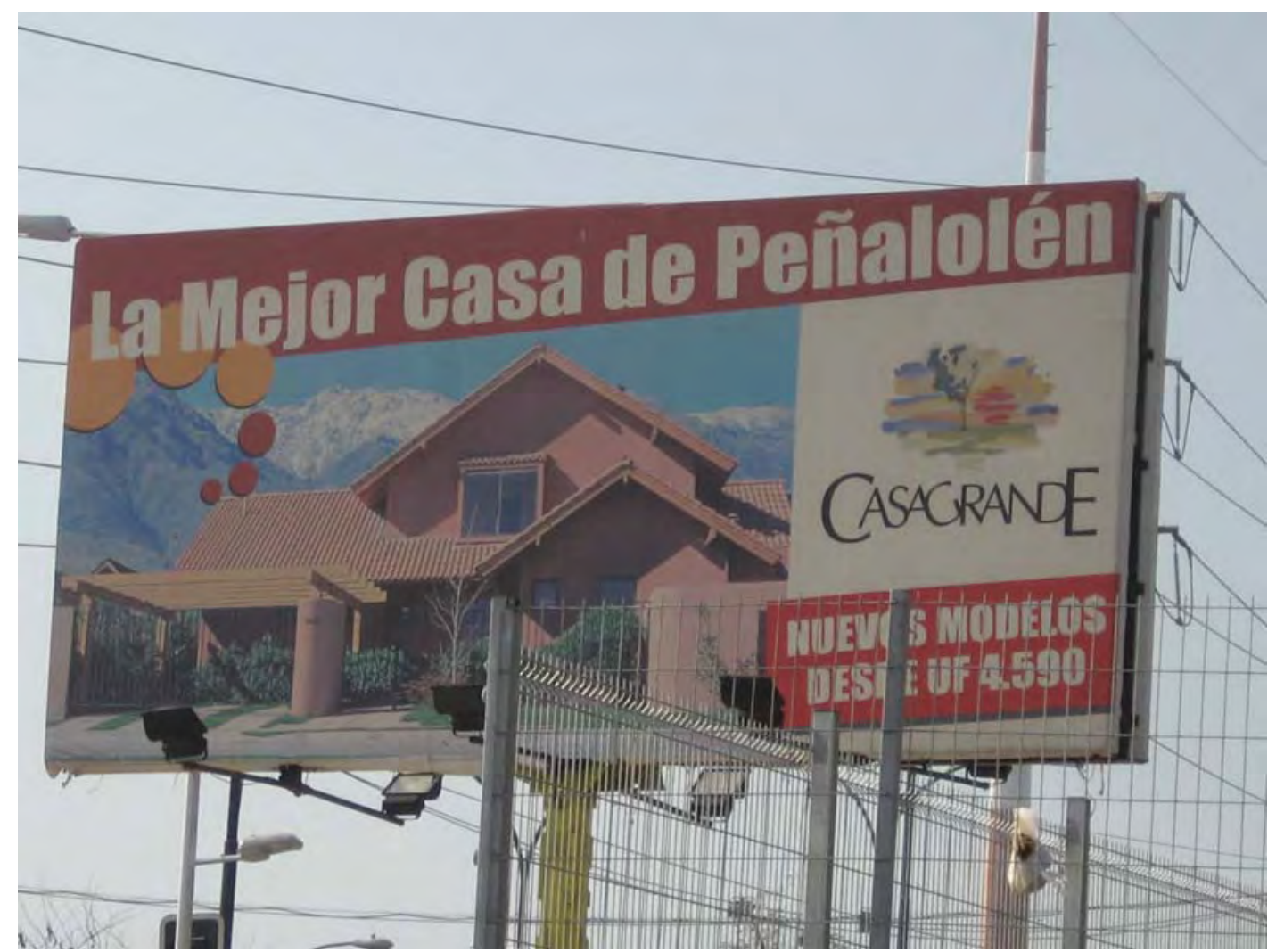

IMAGEN 1. Letrero publicitario de Condominio Casa Grande, en Peñalolén. La casa exhibida es un ejemplo típico de las casas de los barrios cerrados de la comuna. Se resalta también la ubicación, con la Cordillera de Los Andes en el fondo del dibujo (fotografía propia, mayo de 2008).

2. Segregación residencial en escala geográfica reducida: ¿una nueva tendencia distributiva?

Si bien se ha descrito recién cómo en Santiago las comunas pueden asociarse a un destino o grupo social determinado más o menos homogéneo, es un hecho que algunas comunas como Peñalolén y Huechuraba, originalmente ocupadas exclusivamente por habitantes de bajos ingresos, han sido escenario de un nuevo patrón de distribución residencial, convirtiéndose en foco de inversión inmobiliaria a través de la construcción de grandes proyectos destinados a habitantes de nivel socioeconómico alto, medio-alto o medio. Este fenómeno ha llamado la atención de investigadores como Francisco Sabatini, quien ha planteado estas comunas como ejemplo de una nueva tendencia distributiva de los habitantes de Santiago: la reducción de escala geográfica de la segregación residencial socioeconómica: "Debido a su peculiar racionalidad económica y espacial, el fuerte sector de promoción inmobiliaria que ha emergido de la liberalización de los mercados urbanos estaría provocando una reducción en la escala 
geográfica de la segregación social en Santiago [...] la reducción de escala de la segregación es una tendencia estable". (Sabatini, 2000:15). Este fenómeno consiste en el acortamiento de las distancias geográficas entre residencias de grupos de altos y bajos ingresos, contrario al patrón clásico de Santiago de gran escala de segregación según el cual altos y bajos ingresos no coexisten en una misma comuna. En el caso de Peñalolén y Huechuraba, son familias de altos o medios ingresos las que abandonan su sector tradicional de residencia dentro del cono oriente para asentarse en nuevas alternativas residenciales más bien periféricas, aunque aledañas al cono.

El hecho en sí mismo no es cuestionable: en ciertas comunas, originalmente pobladas por grupos de extrema pobreza que se instalaron ya sea por cuenta propia inicialmente en tomas de terreno y campamentos ilegales- o que fueron erradicados desde campamentos del cono oriente, efectivamente se observa la llegada, desde hace un par de décadas, de grupos de ingresos altos y medios. Así se explica la localización de la casa de mi compañera en una comuna como Peñalolén. Su necesidad de dar explicaciones responde en parte a la novedad del fenómeno en aquellos años.

Como señalan Sabatini y Cáceres (2004), "hasta hace una o dos décadas, comunas como Peñalolén eran percibidas como comunas pobres o populares; ahora, después de haber recibido numerosos barrios cerrados, las percepciones se refieren a sectores de las comunas y no a estas como totalidades. No se puede decir que Peñalolén sea una comuna pobre; hay que especificar sectores internos de ella" (2004:31-32). Mientras vastos sectores de Peñalolén se componen por poblaciones que nacieron como tomas de terreno - Lo Hermida o Esperanza Andina ${ }^{3}$, también encontramos grandes condominios de acceso restringido, demarcados por altos muros y alambres de púa o cercos electrificados nada sutiles, cuidados por guardias, compuestos por viviendas de familias homogéneas socioeconómicamente (aunque entre un condominio y otro pueden variar, desde ingresos medios a altos) que han ido estableciendo sus residencias ahí desde hace unas dos décadas. La oferta de este tipo de vivienda continúa desarrollándose con proyectos inmobiliarios que se publicitan con frases como "En el barrio La Hacienda vive más cerca de TODO. Disfruta la naturaleza y

\footnotetext{
${ }^{3}$ Las cuales pasaron de campamentos a su actual condición de poblaciones a través de distintos procesos, más o menos autónomos, pero siempre manteniendo una fuerte conciencia de su origen de toma y campamento, origen que se observa en el presente en otros sectores de la comuna. Es el caso de, hasta hace poco, la Toma de Peñalolén. Los habitantes de esta última se encuentran, desde hace un par de años, desperdigados por distintos puntos del municipio o incluso en otras partes de Santiago (como habría ocurrido en su totalidad si algunos no hubiesen peleado por quedarse en la comuna cuando los obligaron a abandonar la toma) en conjuntos de viviendas sociales.
} 
vive cerca de malls, colegios y centros comerciales" (Parque Cousiño Macul); "En Peñalolén... un barrio ideal para tu familia" (Los Viñedos del Consistorial); o "Dos grandes proyectos para vivir a otra altura" -haciendo un juego de imagen y palabras que alude a la localización geográfica de Peñalolén en el sector alto-precordillerano de la ciudad, además de una insinuación del nivel social- (Condominio El Santuario y Alto Macul). Todos estos avisos (Revista Vivienda y Decoración, 2008. El Mercurio, sábado 29 de marzo de 2008) utilizan frases e imágenes que aluden a conceptos como barrio, naturaleza, parque y cerrado, tranquilidad, a la vez que accesibilidad a colegios y centros comerciales. Muchos de los nombres de los conjuntos habitacionales hacen alusión a las viñas que originalmente ocupaban gran parte de esta comuna, ya que se emplazan precisamente sobre ellas -aunque algunas sobreviven hasta el día de hoy, reducidas. Así se refuerza y enfatiza la cercanía a la naturaleza y a un estilo de vida semi-rural, pero urbano al mismo tiempo. Otra característica es que ofrecen diferentes (2 ó 3) estilos de casa -que podríamos llamar "globales" y homogéneos, en el sentido de que son síntesis simplificadas de estilos arquitectónicos clásicos de todas partes del mundo: estilo inglés, mediterráneo, francés, incluso estilo "chileno"- entre los cuales el cliente puede elegir. Esta característica es compartida con los barrios cerrados de otras partes del mundo, idea masificada originalmente en Estados Unidos, e imitada en muchos países como por ejemplo Argentina. 


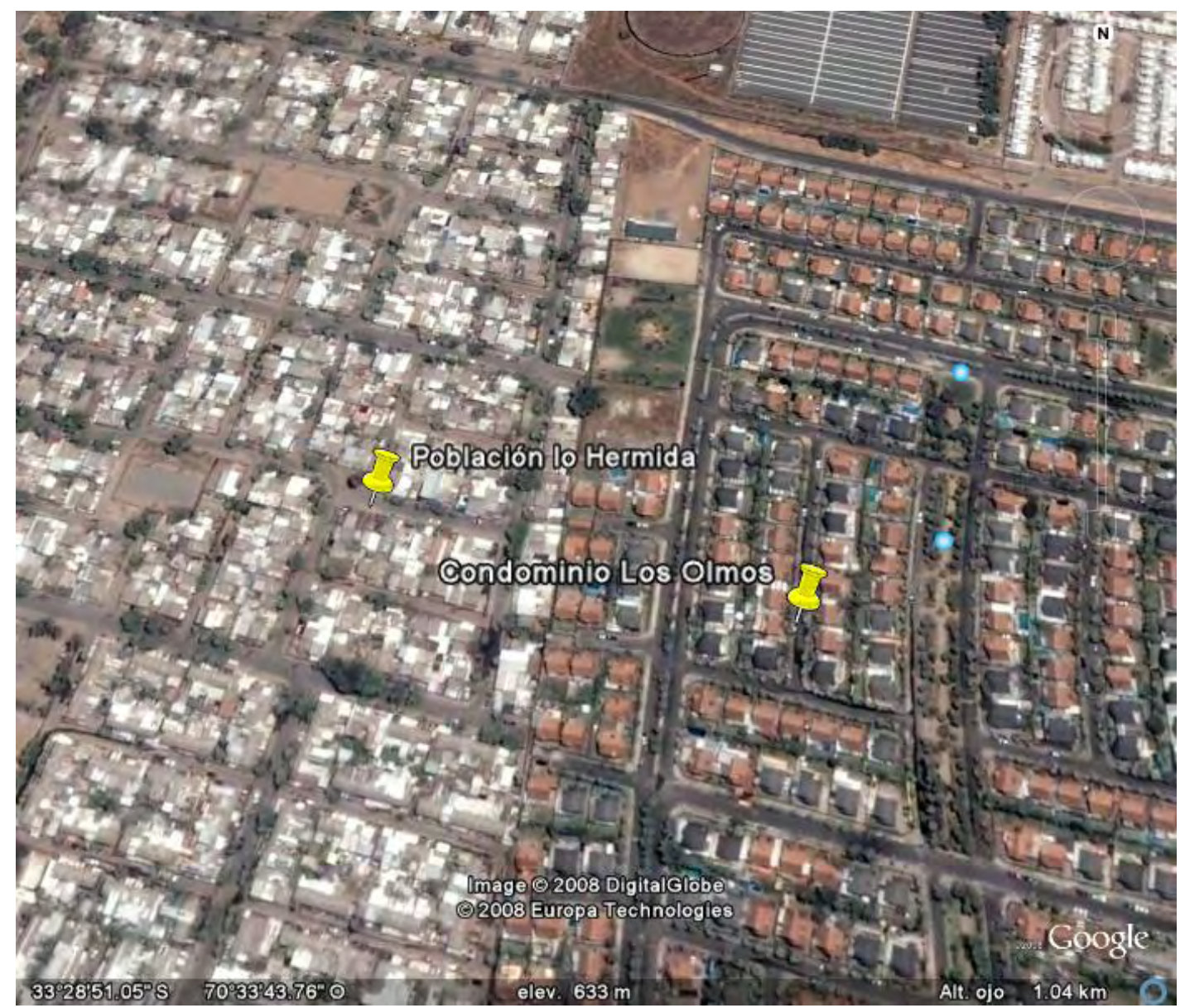

IMAGEN 2. Vista aérea de Peñalolén: a la izquierda, sector El Parral, población lo Hermida. Derecha: condominio El Olmo. Al centro, el muro. (Imagen tomada en Google Earth)

Así, al recorrer la comuna de Peñalolén se observa el despliegue discontinuo de este tipo de conjunto habitacional intercalado con las poblaciones originales. En la IMAGEN 2 se observa desde el aire el contraste que hay entre ambos en cuanto a materialidad y densidad. Mientras las casas -aisladas- del Olmo se distribuyen ordenada y homogéneamente en espacios amplios, con antejardines y entradas para vehículos relativamente generosos (IMAGEN 3), y las calles son lo suficientemente anchas para tener un pequeño bandejón central con árboles (IMAGEN 7), en El Parral las casas son mayormente pareadas, heterogéneas en materiales y diseños -que han sido más bien improvisados y en los que ha sido prioritaria la ocupación de todo el espacio disponible-, con estrechas entradas para autos si es que las tienen (IMAGEN 4), y las calles son angostas y con escasos árboles y áreas verdes (IMAGEN 8).

La discontinuidad es acentuada por la evidencia de los límites de los condominios cerrados -cuya brusquedad se observa también en la IMAGEN 2- y por el 
estilo arquitectónico que los caracteriza -que tiene más en común con otros barrios cerrados del Pilar en Buenos Aires ${ }^{4}$, o de algún suburbio estadounidense, que con las viviendas circundantes-. La cercanía entre uno y otro tipo de conjunto habitacional y, por lo tanto, entre los distintos grupos socioeconómicos, es innegable: el caso del condominio Los Olmos, ubicado inmediatamente hacia el oriente de la villa el Parral, sector de la población Lo Hermida, lo ilustra muy bien. Según se aprecia en las imágenes 6 y 7, los pasajes sin salida del extremo oriente de la población terminan en un gran muro que ha ido creciendo en altura con el tiempo, además de agregársele cada vez más alambres de púa. Unos 5 metros más lejos comienzan las casas de Los Olmos, un condominio de familias de nivel socioeconómico medio. Los guardias declaran que un par de veces han entrado niños "de al lado" (del Parral) a intentar robar a las casas del condominio, pero siempre los han pillado antes. Sin embargo, el condominio ha reforzado su cierre.
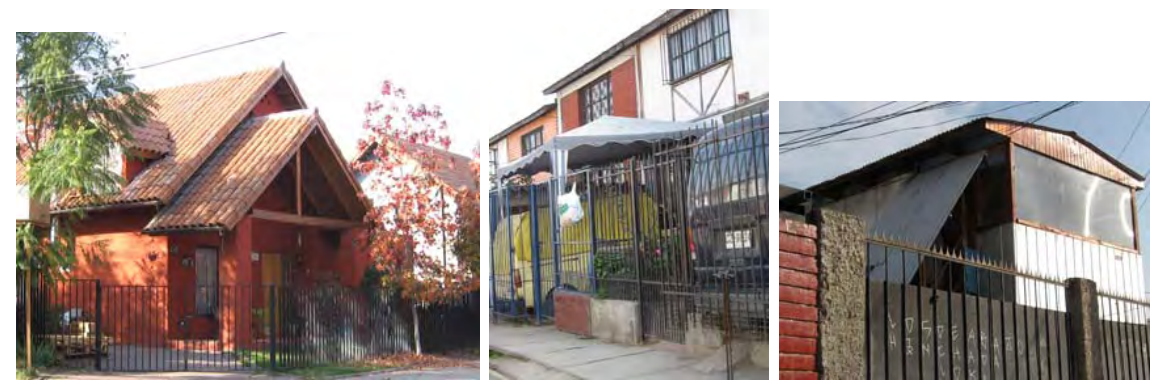

IMAGEN 3. Casa-tipo condominio El OImo; IMAGEN 4. Casas en El Parral (fotos propias, mayo de 2008)

Ahora podemos entender mejor la respuesta de mi compañera: "vivo en Peñalolén, una comuna originalmente ocupada por puros rascas, pero yo vivo en el Parque Tobalaba, no en cualquier parte de la comuna, sino en un barrio cerrado ocupado por gente como yo, como nosotras". El Parque Tobalaba fue uno de los pioneros, además de ser uno de los más extensos. Ocupado por familias de clase media, cuando recién se instaló, a comienzos de los años 90, su diferencia con el entorno resultaba chocante (ubicado al lado sur de Avenida Grecia, eje principal de la comuna, contrastaba con la precariedad de las poblaciones del lado norte de la misma). Sin embargo, podría decirse que hoy, en comparación con otros condominios más

\footnotetext{
${ }^{4}$ El caso de Santiago tiene cierta similitud con el de Buenos Aires (y con otros de América Latina), como se observa al comparar el caso de Peñalolén con el del Pilar, estudiado y descrito por Thuillier (2005).
} 
nuevos, más cerrados y ocupados por familias de más altos ingresos, no parece marcar una discontinuidad tan acentuada.

Si bien el acercamiento físico de grupos sociales diferentes es innegable, dos puntos son discutibles al respecto. Primero, ¿se tratará realmente de una nueva tendencia, o constituye un hecho aislado? Y, segundo, ¿son los efectos de este fenómeno positivos o negativos en términos de integración social?

La primera pregunta se refiere a si puede plantearse el caso de estas comunas como representativo de nuevos comportamientos urbanos en Santiago, que se reproducirán y extenderán su influencia al resto de la ciudad, o si se trata de un fenómeno circunstancial que, como tal, se limita a la ocurrencia de ciertas condiciones muy particulares y por lo tanto no será un fenómeno que se extienda al resto de la población de Santiago ni a un porcentaje mayor de ella. Se trate o no de una nueva tendencia en este sentido, quienes apuestan por los efectos positivos en cuanto a integración social consideran necesario promover desde las políticas públicas el que este fenómeno se transforme en una verdadera tendencia. ¿Cómo? Incentivando la acción del gran promotor inmobiliario, a quien se considera el mayor responsable del fenómeno (Sabatini, 2000). Francisco Sabatini (2000) plantea la hipótesis de que la reducción de la escala geográfica de SRS sería consecuencia de la liberalización de los mercados del suelo a partir de 1979, evento que si bien tiene mayormente consecuencias negativas desde el punto de vista de la integración social y de la agudización de la SRS en gran escala, a través del alza de los precios del suelo generó condiciones para el surgimiento de la figura del gran promotor inmobiliario, que tiene la capacidad de generar grandes proyectos como los de Peñalolén, que no consisten solo en la construcción misma de las viviendas, sino en la dotación de la infraestructura urbana necesaria para lograr cambiar el destino social del suelo. $Y$ en eso consiste precisamente una de las estrategias de ganancia de este agente: invertir en tierra que debido a su ubicación en un sector de bajo nivel socioeconómico, mal dotado de infraestructura pública, más o menos periférica, se vende a muy bajo precio. Posteriormente desarrollar proyectos lo suficientemente grandes como para compensar la mala infraestructura comunal y hacer atractivo el sector para otros grupos socioeconómicos, sacando partido a la lejanía respecto de la ciudad congestionada, cercanía a espacios naturales, y la disponibilidad de terrenos grandes. Así se maximiza la rentabilidad de la tierra: “...grandes proyectos residenciales apoyados en estrategias 
de marketing [...] pueden atraer a demandantes de estratos altos o medios hacia localizaciones en los intersticios o las cercanías de áreas de ingresos menores [...] compran tierra a "precio obrero" y la venden, mejorada (construida), a precios correspondientes a la condición social de los recién llegados" (Sabatini, 2000:17).

Así como el gran promotor inmobiliario sería el responsable de la reducción de escala, dentro de la misma hipótesis, sostiene Sabatini que los agentes responsables de la consolidación del patrón de gran escala de SRS en el caso de Santiago serían tres: el pequeño promotor inmobiliario, quien por su incapacidad de modificar el destino social del suelo sólo invertiría en sectores de un determinado destino social, para realizar proyectos correspondientes al mismo estrato socioeconómico que ya lo ocupa; el Estado de Chile, el cual en vista de los precios del suelo ha desarrollado proyectos de vivienda social en los sectores periféricos de la ciudad para abaratar costos; y el ocupante o invasor ilegal de tierras, quien en un intento por evadir la represión y evitar riesgos de expulsión de la tierra ocupada, ha optado por ocupar terrenos en sectores también periféricos de poco interés para los inversionistas inmobiliarios y la sociedad en general.

En base a lo anterior, para este investigador promover la tendencia hacia la reducción de escala de segregación significa promover la acción del gran agente inmobiliario. En esta dirección de modificación de destino social de áreas o comunas, se promueve el mismo fenómeno en sentido contrario: el desarrollo de proyectos de vivienda social en sectores de mayores ingresos, bajo la lógica de que, así como ha subido el precio de los terrenos donde se han construido estos proyectos cambiando el destino social del sector, podría bajarse el precio del suelo donde se construyan viviendas de más bajo valor. Sin embargo, esto es muy difícil dado que, apoyados en estrategias de marketing, los agentes inmobiliarios pueden vender sus proyectos en cualquier localización. La pregunta entonces es, ¿por qué habrían de bajar los precios como consecuencia de la localización de nuevos grupos de menores ingresos? Sabatini ha señalado como uno de los efectos negativos de la reducción de escala de SRS y la masificación de condominios cerrados, el alza generalizada de los precios del suelo, incluso en sectores que hasta hace poco valían muy poco para los inversionistas (2004:33). Todo lo anterior, porque considera que la reducción de escala de SRS puede generar efectos positivos y condiciones que permitan la integración social entre diversos grupos socioeconómicos. 

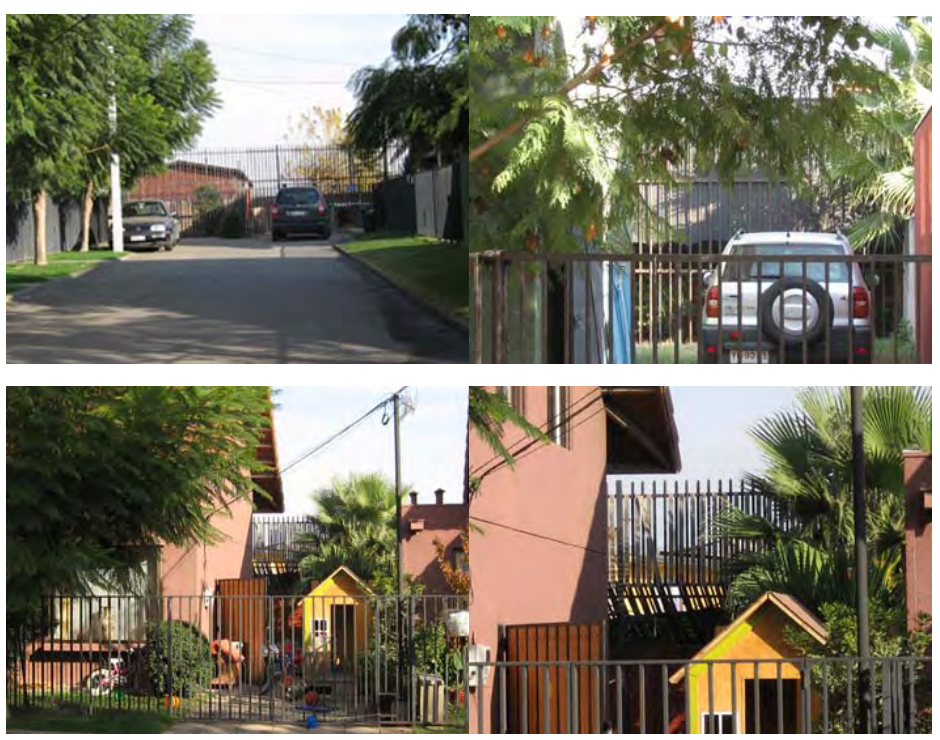

IMAGEN 5. El límite entre el condominio y la población, visto desde El Olmo: el muro-reja se ubica en el patio trasero de las casas que limitan con El Parral, y al final de los pasajes (fotos propias, mayo de 2008).

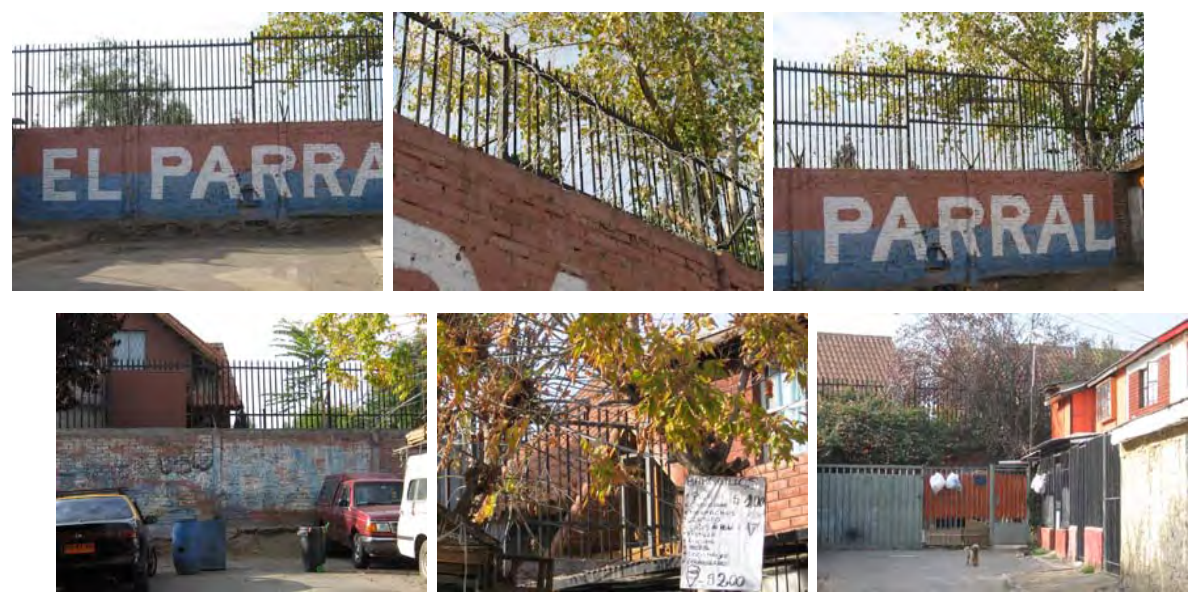

IMAGEN 6. Límite visto desde El Parral: los pasajes terminan en el muro, o el muro coincide con la pared lateral de las casas limítrofes. La casa roja que se ve detrás del muro en la imagen inferior izquierda, corresponde con la de la IMAGEN 5. En la imagen inferior-centro se aprecia la cercanía: el tejado corresponde a una casa de El Olmo, el ladrillo a una del Parral (fotos propias, mayo 2008).

\section{Efectos de la reducción de escala geográfica de SRS: el largo y corto plazo}

Más importante que determinar si efectivamente se trata o no de una tendencia que vaya a generalizarse, es determinar si tiene o no efectos socioespaciales positivos, tanto actualmente constatables como en potencia. Es decir, si es o no conveniente que la SRS en escala reducida se transforme en una tendencia generalizada y estable. 
Entonces, ¿cuáles son los actuales efectos y potencialidades, en cuanto a consecuencias espaciales y sociales, de la reducción de escala de SRS en Santiago?

\subsection{El largo plazo: ¿integración o gentrificación?}

Una preocupación respecto a las consecuencias de largo plazo que podría mostrar este fenómeno es que de aquí a un tiempo descubramos que ya no se trata de una reducción en la escala geográfica de la SRS, sino que se trataba de una etapa inicial de un proceso de gentrificación -es decir, desplazamiento y reemplazo de un grupo social por otro en un espacio-, constituyendo en realidad una expansión del cono oriente hacia el sur ${ }^{5}$. Así, tal vez en un par de décadas más no encontremos en Peñalolén la coexistencia de conjuntos habitacionales socialmente heterogéneos, sino la sola existencia de habitantes de medios y altos ingresos que desplazaron a los habitantes originales de bajos ingresos, ya sea comprando las empresas inmobiliarias sus terrenos, o impidiendo el establecimiento de las nuevas familias originarias de la comuna, debido al alza sostenida de los precios del suelo, que hace cada vez más difícil la construcción de proyectos de vivienda social en el sector.

Hasta el momento, se han observado ya ciertos conflictos entre los distintos grupos de intereses que coexisten en Peñalolén. Por ejemplo al expulsarse a los habitantes de la Toma de Peñalolén para la supuesta construcción de un parque cerrado en el terreno que ésta ocupaba. La idea era trasladar a la gente de la toma hacia otras comunas como La Florida, desorganizando a este grupo de personas que durante años vivió y trabajó unido. Tras la pelea que dieron algunos, lograron quedarse, al menos parte de ellos, en Peñalolén, desperdigados en distintos sectores, en casas construidas con el subsidio estatal por las cuales incluso antes de su estreno tuvieron que enfrentar conflictos con los vecinos de la Comunidad Ecológica -conjunto residencial cerrado consistente en parcelaciones en las cuales los compradores han construido sus propias casas, distinto en este aspecto a los condominios de los que se ha hablado antes-, con un sentido ecológico como motivo unitario. En tal lugar, rostros conocidos de la farándula artística chilena tienen sus propiedades, y postulan un estilo de vida "natural", podría decirse hippie, a pesar del cual a muchos de ellos no les agradó la idea de tener instalados al lado a los antiguos habitantes de la Toma de Peñalolén, percibidos como

\footnotetext{
${ }^{5}$ En la tesis de grado de la geógrafa Alejandra Elgueta (2006) se estudia esta hipótesis.
} 
posibles delincuentes. En una entrevista a una moradora de este conjunto pregunté si a veces entraban personas de afuera, refiriéndome a las actividades que se realizan en el interior, tales como teatro, talleres artísticos, viveros, etcétera. Su respuesta fue tajante: "sí, entran a robar".

En "La Guerra y la Paz Ciudadana" (Ramos y Guzmán de Luigi, 2000) se relata otro conflicto más antiguo de la comuna: los pobladores del campamento Esperanza Andina habían conseguido el subsidio para transformar el campamento en población, es decir para construir sus casas. Pero para la construcción de las mismas tenían que abandonar el sitio por un año. La municipalidad les cedió un terreno baldío de la comuna, el cual podían ocupar por un año. Bastó el aviso de esta situación para que los moradores de un condominio cerrado aledaño al terreno se indignaran y finalmente impidieran que esto ocurriera.

Estos conflictos hacen pensar en el ánimo que hay por parte de los nuevos habitantes hacia los originales, y en la clara inclinación a favor de los primeros que muestra la resolución oficial de los conflictos y, por lo tanto, en cómo pudiera evolucionar la SRS en escala reducida si continúa la demanda por conjuntos residenciales cerrados en este sector. Algo que queda claro es que, más allá de que en la práctica se produzcan o no situaciones de integración social, no es ésta uno de los motivos por los cuales familias de medios o altos ingresos eligen la comuna de Peñalolén para vivir.

\subsection{El corto plazo: ¿integración, conflicto o indiferencia social?}

¿Cuáles son los efectos inmediatos que tiene la cercanía geográfica de las residencias de grupos ricos y pobres? Sin importar si se trata de una tendencia generalizada o de un caso aislado dentro de Santiago, ni si se mantendrá en este estado o mutará hacia otro tipo de fenómeno, es necesario conocer el impacto que actual e inmediatamente tiene, para saber si queremos que se convierta en una tendencia generalizada o si con políticas que la incentiven podría estar reforzándose un fenómeno que tal vez no sólo no traiga consigo las consecuencias positivas de tipo social que algunos esperan, sino que, por el contrario, tenga efectos inmediatos negativos y hasta perversos en ese ámbito.

Tanto Francisco Sabatini (2000) como Alfredo Rodríguez (2001) suponen efectos positivos en términos de integración social para la reducción de la escala 
geográfica de SRS. Sabatini plantea los espacios "públicos" de consumo, la necesidad de mano de obra doméstica por parte de los nuevos habitantes, y de empleo por parte de los antiguos como posibles puntos de encuentro e integración. Sin embargo, se trata de instancias propicias para la reproducción de relaciones asimétricas que no cambian en nada la situación social de cada grupo, ni las de cada persona o familia, ni la relación estructural entre los diferentes grupos. Los espacios de consumo son abordados de maneras muy distintas según la capacidad de consumo de cada uno, además de que las personas son recibidas y tratadas diferenciadamente en estos espacios, según esa misma capacidad y condición social. Las posibilidades de empleo consisten en trabajos por lo general mal remunerados, y por los cuales hay una gran competencia (Thuillier, 2005). Como señalan Ramos y Guzmán de Luigi (2000), en nuestra sociedad, durante la década de los 90:

El contacto entre personas de distinto nivel económico quedó reducido así, a áreas en las que no eran posibles relaciones igualitarias: el trabajo, donde Chile presenta niveles enormes de autoritarismo, de abuso y de falta de regulaciones; el mercado, al cual se tiene acceso de acuerdo a ingresos notablemente mal distribuidos; y los medios de comunicación, donde pobres y ricos confluyen para ver reflejadas sus enormes diferencias, sin mayores cuestionamientos y como una especie de espectáculo de la vida. (Ramos y Guzmán de Luigi, 2000: 26)

Por otra parte, los espacios e instancias públicas recreativas-educativas municipales son enfocados hacia los grupos de escasos recursos de la comuna, y la generación de espacios públicos nuevos resulta a veces conflictiva, en el contexto de un territorio limitado, que gana valor comercial -para grupos económicos poderosos- y residencial -para familias de altos ingresos-, obstaculizando el acceso o permanencia a los habitantes originales, y generando conflictos de intereses entre ellos.

Un joven de Lo Hermida me contaba que cuando niño jugaba con sus vecinos en un terreno baldío que era parte de los viñedos, para ingresar al cual solo tenían que traspasar los alambres del cerco que lo separaba de su pasaje. Pero un día en ese terreno se construyó un condominio cerrado, y nunca pudieron traspasar esos muros. Por mucho tiempo planearon en medio de juegos la construcción de una bomba para tirar hacia el condominio, y aunque jamás lo hicieron, las ganas siempre estuvieron, entre la broma y la verdad.

La situación descrita hace suponer relaciones "cara a cara" conflictivas o indiferentes, no-relaciones, más que en relaciones de integración social (enfatizo en el cara a cara, ya que si pensamos en relaciones indirectas -como la idea o percepción que 
un grupo de personas pueda tener sobre otras, sin conocerlas como individuos, sino como categoría social- sí puede suponerse que este acortamiento de las distancias al menos genere una toma de conciencia de un grupo respecto del otro, o modifique en algo su percepción). Hasta aquí, sin embargo, me quedo nada más que en suposiciones en base al trabajo de campo propio y la literatura citada.

Si bien la investigación cualitativa, a través por ejemplo del trabajo de campo que la antropología puede aportar en esta discusión, resulta absolutamente necesaria para vislumbrar los efectos del fenómeno en términos de integración social, es prerequisito aclarar asuntos teóricos y conceptuales que guíen dicha investigación.

Existe una coherente explicación teórica para comprender por qué la integración social no resulta obvia ni natural como efecto de este acercamiento entre grupos diversos, en las actuales condiciones sociales, económicas e históricas de Santiago y de gran parte del mundo. Es necesario tener presentes algunas definiciones en base a las cuales se plantea teóricamente el tema, siendo el principal punto en cuestión la forma en que se valora y evalúa la reducción de escala de la SRS, y no su ocurrencia. En gran parte, las diferencias de opinión varían de acuerdo a las definiciones que se manejen, por ejemplo, de integración social y de distancia física, que en conjunto conforman la definición de segregación residencial socioeconómica.

Entre las definiciones citadas, una bastante general desde la que se puede partir es la de Sabatini (Rodríguez 2001:12): "En términos simples, segregación espacial o residencial es la aglomeración geográfica de familias de una misma condición o categoría social, como sea que se defina esta última, social o racialmente o de otra forma".

También general, pero aplicada específicamente a la diferenciación socioeconómica, es la siguiente: "ausencia o escasez relativa de mezcla socioeconómica en las subunidades territoriales de una ciudad" (Rodríguez 2001: 7).

Sabatini (Rodríguez 2001:12) especifica 3 dimensiones de la segregación: primera, la tendencia de un grupo a concentrarse en un área determinada, sin necesariamente implicar que en esa área no existan otros grupos; segunda, la conformación de áreas socialmente homogéneas, con ausencia de mezcla de grupos en un mismo espacio; y una última dimensión subjetiva que se refiere a la percepción que las personas tienen de las otras dos dimensiones objetivas. 
La primera definición, del mismo Sabatini, corresponde más bien a la primera dimensión, mientras la de Rodríguez coincide con la segunda. Aglomeración y ausencia de mezcla son los elementos esenciales de la segregación en estas definiciones, correspondientemente. Aunque la distancia no aparece mencionada explícitamente, Sabatini y Cáceres (2004) precisan que "La segregación residencial es, en último término, una cuestión de distancia física entre personas de distinta categoría social, y del aislamiento entre grupos a que esa distancia contribuye" (2004:11).

Por su parte, Rodríguez distingue dos "tipos" de segregación: uno en términos sociológicos, que significa la ausencia de interacción entre grupos sociales, y uno en términos geográficos, que significa desigualdad en la distribución de los grupos sociales en el espacio físico. Al respecto señala que "la presencia de un tipo de segregación no asegura la existencia del otro" (Rodríguez 2001:11). Tal vez no debieran llamarse "tipos", ya que no se trata de modalidades excluyentes una de otra, sino que son más bien dimensiones desde las que puede entenderse, definirse y evaluarse la segregación. De hecho, creo que no es posible entender, definir ni evaluar integralmente la segregación si no es desde esas dos dimensiones interrelacionadas.

Si bien Rodríguez hace esta distinción, su trabajo y propuesta se enfoca en la segregación en sentido geográfico, y la dimensión social queda relegada al plano de "hipótesis de trabajo", sin ahondar en este plano: "Aunque sólo sea una hipótesis de trabajo, la reducción de la escala de la segregación residencial debiera atenuar su importancia como inhibidora de la interacción entre grupos socioeconómicos distintos". (Rodríguez 2001: 31). Lo mismo puede decirse de Sabatini, quien postula efectos de integración social en base a suposiciones teóricas y algunas observaciones cualitativas propias y de otros investigadores, afirmando que: "a pesar de las marcadas desigualdades sociales que ha traído la globalización económica a Chile, la escala geográfica de la segregación en Santiago podría estar retrocediendo, abriendo oportunidades inéditas y específicamente urbanas de integración social" (Sabatini 2000: 17).

Tal similitud en las suposiciones no es coincidencia. Por un lado, ambos autores han utilizado una metodología principalmente cuantitativa, con algunas observaciones cualitativas, para evaluar la SRS. Esta metodología permite, efectivamente, diagnosticar la modalidad de la SRS, y el aumento o reducción de su escala geográfica. Sin embargo, las técnicas cuantitativas no abarcan de ningún modo la 
dimensión sociológica definida por Rodríguez (sí abarcan aspectos sociológicos específicos en los indicadores en base a los cuales se definen los grupos sociales y la ausencia o presencia de segregación, pero no en términos de la interacción social como efecto o defecto de las modalidades de SRS). La geográfica es abarcada incompletamente, ya que al referirse a la distancia como un atributo exclusivamente cuantitativo, no contemplan aspectos geográficos como la modalidad de localización, que puede ser abierta o cerrada, continua o discontinua, accesible o inaccesible, etcétera. Entonces, lo que no es abarcado por la metodología utilizada debe ser supuesto, y no es extraño suponer que a mayor cercanía física, en términos de metros o kilómetros que separan a un grupo de otro, mayor será la posibilidad de contacto e integración social. Parece lógico, y así habría sido, seguramente, hasta hace unos 50 años. Pero estas suposiciones no tienen en cuenta el nuevo contexto en que este fenómeno se ha venido a desarrollar, contexto que no es circunstancial o contingente, sino que es en sí mismo lo que posibilita la reducción de escala geográfica de la SRS: tecnologización del hogar, privatización de servicios y expansión global de la modalidad habitacional de "barrios cerrados", lo cual en conjunto tiene como consecuencia la pérdida de la importancia del lugar o localización.

Manuel Castells (1998), sin referirse directamente a la segregación residencial, plantea la teoría de la superposición de lógicas espaciales, el paso diferenciado desde la lógica del espacio de los lugares, a la lógica del espacio de los flujos, por parte de algunos sectores de la sociedad.

El lugar es definido como "localidad cuya forma, función y significado se contienen dentro de las fronteras de la contigüidad física" (Castells, 1998:35), mientras los flujos serían "secuencias de intercambio e interacción determinadas, repetitivas y programables entre las posiciones físicamente inconexas que mantienen los actores sociales en las estructuras económicas, políticas y simbólicas de la sociedad" (1998:29). Según esta teoría, las tecnologías de la información, sumadas a las formas y procesos sociales inducidos por el actual proceso de cambio histórico, producirían cambios en el espacio y tiempo, siendo el espacio, en un sentido social, la base material de nuestra experiencia. Señala que

El desarrollo de la comunicación electrónica y los sistemas de comunicación permiten la disociación creciente de la proximidad espacial y la realización de las funciones de la vida cotidiana -trabajo, compras, entretenimiento, salud, educación, servicios públicos, gobierno y demás [...] La interacción de la nueva tecnología de la información y los procesos actuales de 
cambio social tiene un impacto sustancial sobre las ciudades y el espacio [...] la disposición de la forma urbana se transforma considerablemente. Pero esta transformación no sigue un modelo único y universal [...] depende de las características de los contextos históricos, territoriales e institucionales. (Castells 1998: 19-22).

En el caso analizado, las tecnologías de la información se ven representadas por la tecnologización doméstica -es decir, la extensión de la tecnología informática y de otros tipos al hogar, y por ende a la vida cotidiana- y de la infraestructura pública, sumada al actual proceso de cambio histórico que se manifiesta en los cambios particulares de Chile y de la ciudad de Santiago como son la privatización de una parte de la oferta de servicios (educación, salud, recreación), paralela a la municipalización de la oferta pública, además de la creación y paulatina masificación de nuevas formas de asentamientos urbanos como los barrios cerrados ${ }^{6}$.

La reducción de escala geográfica de la SRS no sería posible sin este desarrollo tecnológico y su entrada relativamente masiva al ámbito doméstico (acceso a nivel familiar a estas tecnologías, sin necesidad de acudir a un lugar especializado tecnológicamente): vías expeditas de tránsito urbano, extensión de vías de metro, perfeccionamiento progresivo de automóviles, Internet y sus instancias de sociabilidad virtual -como MSN, Fotolog, Youtube, My Space, Facebook, y similares-, televisión por cable y satelital, reproductores de audio y sonido digitales, consolas de videojuegos, etcétera. Al actuar conjuntamente la tecnologización doméstica, el formato residencial de barrio cerrado, y la privatización de los servicios, permiten la entrada de una parte de la sociedad a la lógica del espacio de los flujos, y su consecuente abstracción del lugar, lo que permite que se le reste importancia a la localización, gozando de una libertad nunca antes observada para escoger el lugar de asentamiento y sin importar lo que haya a su alrededor. Se llega del trabajo a la casa a través de vías cada vez más expeditas, en automóviles en los que cada vez se notan menos las imperfecciones de las calles (esto determina al automóvil como burbuja, ver Amándola, 2000), y se llega a condominios cerrados desde donde el exterior es invisibilizado, y dentro de casa se tiene acceso virtual a todo el mundo, partiendo por los amigos y familiares localizados en otras áreas de la capital. Los niños asisten a colegios particulares, las compras pueden ser realizadas en malls o grandes supermercados (o mediante Internet, aunque esta forma

${ }^{6}$ Considero discutible utilizar el concepto de barrio para referirse a estos conjuntos habitacionales cerrados. Si bien es el nombre que se les ha asignado en la publicidad y ya es un nombre reconocido por todo el mundo, la investigación social sobre el tema debiera cuestionárselo. Sin embargo no me referiré mayormente a este punto ahora, ya que escapa del tema central de este artículo. 
de consumo no ha tenido la masificación e impacto esperados) y se accede a servicios privados de salud y recreación, ya sea dentro o fuera de la comuna, ya que si bien en Peñalolén se ha localizado todo tipo de oferta privada de servicios, lo principal es que, como ha señalado Castells (1998), la lógica del espacio de los flujos tiene por esencia la disociación creciente de la proximidad espacial y la realización de las funciones de la vida cotidiana: "es fundamental que separemos el concepto básico del soporte material de las prácticas simultáneas de la noción de contigüidad física, con el fin de dar cuenta de la posible existencia de soportes materiales de la simultaneidad que no se basan en contigüidad física, ya que este es precisamente el caso de las prácticas sociales dominantes en la era de la información". (1998:29). Por un lado, estas familias pueden acceder a los servicios que necesitan diariamente en cualquier zona de la ciudad, o incluso sin moverse de sus casas, pero por otro los prestadores de servicios privados pueden localizarse también en cualquier área, por lo cual se han acercado a las nuevas zonas de desarrollo residencial periférico, permitiendo a sus habitantes mantenerse en cierto grado dentro de la lógica del espacio de los lugares.

Desde esta perspectiva, el gran agente inmobiliario no es, como plantea Sabatini (2000), el elemento único ni principal en la reducción de la escala de SRS. Su acción apunta a la construcción de barrios cerrados, que es uno de los factores que, en conjunto con otros, permiten la ocurrencia de este fenómeno. Así mismo, no son las estrategias de marketing por sí solas las que convencen a numerosas familias de medios y altos ingresos de instalarse en comunas pobres y periféricas. La decisión depende de las posibilidades que tenga la familia de acceder a la nueva lógica espacial de los flujos. Es decir, posibilidades de disponer de la cantidad de automóviles necesarios (y del combustible correspondiente) para cubrir la necesidad de desplazamiento intra-urbano de los miembros de la familia; computadoras con acceso a Internet, banda ancha, y también según la demanda de los miembros de la familia (si tienen más de un hijo de entre 10 y 30 años, seguramente no baste con un computador); televisión satelital, aparatos de reproducción audiovisual de última generación, costear una casa ubicada en un barrio cerrado y los altos gastos comunes de cobro mensual, colegios privados para todos sus hijos, estar en el sistema privado de salud y, ojalá, tener empleos que permitan cierta flexibilidad horaria e incluso la realización de algunas actividades desde cualquier ubicación. Puede sonar simple, pero el costo total de todo esto supera con creces el ingreso promedio de las familias chilenas y por supuesto el de 
muchas familias de Peñalolén. Sin embargo, es posible para un considerable sector de la sociedad urbana de Santiago.

Todo lo anterior no significa que los lugares desaparezcan. Estas personas, la elite que se sumerge en el espacio de los flujos, siguen viviendo en lugares, pero éste pierde relevancia como elemento significativo, decisivo, definitorio, como parte de la identidad de esa elite. Categorizar las personas en base al lugar de residencia, como por ejemplo el barrio alto o ciertas comunas particulares como La Dehesa, las Condes, etcétera, sólo la define en función de la ciudad de Santiago y de la sociedad particular y local en que viven. En el contexto de las redes y flujos de información, la elite también se globaliza y por lo tanto debe definirse en referencia a parámetros globales, más allá de las fronteras de su ciudad y sociedad local.

Por otra parte, la mayoría de las personas siguen viviendo inmersas en la lógica del espacio de los lugares, sin acceso doméstico a las nuevas tecnologías de la información ni a los servicios privados. Thuillier (2005), sin hacer referencia a la teoría de superposición de lógicas espaciales, describe el mismo fenómeno para el caso de la provincia de Buenos Aires:

Desde el advenimiento de las urbanizaciones cerradas, en lo que concierne a las prácticas y movilidad de los habitantes de la periferia, existen dos modos de vida y dos redes de circulación, de esparcimiento y de consumo, superpuestos pero bastante escindidos, con sus nudos y sus polos de centralidad distintos, que coexisten en la gran periferia de Buenos Aires. (Thuillier, 2005:10)

La nueva lógica se superpone sobre la lógica del espacio de los lugares, de la misma manera que estos nuevos habitantes se superponen sobre los originarios. Los barrios cerrados no sólo protegen a sus habitantes de los posibles actos delictuales y violación de su privacidad: protegen su lógica espacial de la lógica circundante, la del lugar.

La teoría de Castells (1998) se plantea en relación a la economía global, las ciudades y megaciudades, las redes que entre estas se crean, y su funcionamiento a través de la conexión global y desconexión local. Sin embargo, es totalmente aplicable a la forma de asentamiento de los grupos socioeconómicos que participan de esta nueva economía global, dentro de cada ciudad. Son ciudades que pueden estar en diversos puntos jerárquicos de la red global, pero que reproducen internamente dicha jerarquización de red: 
Los nodos del espacio de los flujos incluyen espacios residenciales y orientados al ocio [...] tienden a agrupar las funciones dominantes en espacios cuidadosamente segregados, con fácil acceso a complejos cosmopolitas de las artes, la cultura y el entretenimiento. La segregación se logra tanto por la ubicación en lugares diferentes como por el control de la seguridad de ciertos espacios abiertos sólo para la élite [...] se organiza una serie de jerarquías socioespaciales simbólicas, de tal modo que los niveles de gestión inferiores puedan reflejar los símbolos de poder y apropiarse de ellos mediante la construcción de comunidades espaciales elitistas de segundo orden, que también tenderán a aislarse del resto de la sociedad, en una sucesión de procesos de segregación jerárquicos que, juntos, equivalen a la fragmentación socioespacial. (Castells, 1998:32-33).

La élite, en esta lógica del espacio de los flujos, tendría la

[t]endencia a crear un estilo de vida e idear formas espaciales encaminadas a unificar su entorno simbólico en todo el mundo, con lo que suplantan la especificidad histórica en toda localidad [...] sentimiento de familiaridad con el mundo interior, mientras se induce la abstracción con el mundo circundante [...] estilo de vida cada vez más homogéneo entre la elite de la información que trasciende las fronteras culturales. (Castells, 1998:33).

El formato residencial de barrio cerrado constituye uno de estos símbolos que unifican a la elite global-globalizada, bajo un estilo de vida que la conecta globalmente, y la desconecta de su entorno local, donde

[l]a gente sigue viviendo en lugares. Pero como en nuestras sociedades la función y el poder se organizan en el espacio de los flujos, el dominio estructural de su lógica altera de forma esencial el significado y dinámica de aquellos [...] la consecuencia es una esquizofrenia estructural entre dos lógicas espaciales que amenaza con romper los canales de comunicación de la sociedad[...] quizás nos dirijamos hacia una vida en horizontes paralelos, cuyos tiempos no pueden coincidir porque están urdidos en dimensiones diferentes de un hiperespacio social. (Castells, 1998:37)

\section{Conclusiones: hacia una nueva conceptualización de la SRS}

En base a esta teoría es posible y necesario re-conceptualizar la segregación residencial en su contexto actual. El impacto de que familias de muy altos, medios, bajos y muy bajos ingresos sean ahora vecinas es totalmente diferente hoy, que hace 50 años, cuando de ser vecinos la calle sí habría sido un lugar de encuentro, los niños habrían asistido a las mismas escuelas y habrían jugado en las mismas plazas. Su conexión con el mundo se habría producido a través del lugar, bajo la "limitación" de la contigüidad física (motivo por el cual Santiago se desarrolló, al menos hasta ahora, bajo el patrón de segregación en gran escala). Hoy, en cambio, se accede al mundo por vías diferentes según el grupo y lógica de que se es parte. 
Cuando Castells (1998) plantea que "La articulación de las elites y la segmentación y desorganización de las masas parecen ser mecanismos gemelos de dominio social en nuestras sociedades [...] las elites son cosmopolitas; la gente local" (1998:32), me hace pensar que, en este sentido, en Peñalolén, como se suele decir, "se mata dos pájaros de un tiro": nuevas residencias para la nueva elite global de segundo nivel, por un lado, y por otro gentrificación y consecuente desorganización de los antiguos pobladores (desarme de tomas ilegales y campamentos; alza de precio del suelo que dificulta la permanencia de las familias jóvenes en la comuna; ocupación "legal" de terrenos con fines inmobiliarios privados o para construcción de parques y supermercados para los nuevos residentes, sobre los cuales se proyectaba la construcción de nueva vivienda social para estas nuevas jóvenes familias de la comuna, etcétera).

Un primer punto a considerar en una re-conceptualización de la SRS es que el componente geográfico no se refiere exclusivamente a la distancia física entre los grupos, la heterogeneidad social de un área o a la ubicación de éstos en relación a la ciudad y a los otros grupos. Debe incluir también la observación y análisis del modo en que los grupos se asientan y establecen, integrándose o produciendo quiebres geográficos en su entorno. Aún no me refiero a la integración social, sino física. Es decir, el tipo de asentamiento, los límites y barreras construidas, los accesos y cierres, la continuidad/discontinuidad estética. En síntesis, la forma en que cada grupo o cada conjunto habitacional se localiza, se hace parte del lugar en que se sitúa o genera diferencias con éste, se adapta a él o intenta modificarlo. Estos atributos también forman parte del concepto de distancia física.

Ahora, además de complementar la dimensión geográfica en el sentido señalado, lo principal es que esta nueva conceptualización integre -no sólo señalándolas como dimensiones independientes o paralelas posibles de tomar o no en cuenta- las dimensiones geográfica y sociológica como interdependientes e igualmente relevantes en la definición de la SRS, asociando los modos en que se produce una con los efectos que tiene sobre la otra, y viceversa. Relacionar tanto las dimensiones mismas como sus componentes. En este punto, a la afirmación de Rodríguez agregaría que, así como la existencia de un tipo de segregación no asegura la existencia del otro, tampoco la ausencia o reducción de un tipo asegura la ausencia o reducción del otro: la reducción 
de escala geográfica de la SRS no necesariamente implica una reducción en el grado de segregación en sentido sociológico en el área afectada.

Por otra parte, se hace necesario aclarar lo que se entiende por integración social. No discrepo con Sabatini en cuanto a las posibilidades de nuevos empleos locales que este acercamiento implica: jardineros, asesoras domésticas, limpiadores de piscinas, etcétera. Pero, ¿constituyen estas posibilidades y relaciones laborales una forma de integración social? Son acontecimientos que no deben pasarse por alto, y si comparamos la situación de Peñalolén con la de otras comunas como donde sólo hay habitantes pobres, seguramente encontremos una gran diferencia. Pero para hablar de integración social no basta con encontrar instancias de relaciones, y sino instancias para relaciones simétricas, que puedan generar cambios estructurales en la posición de las personas y los grupos, y en la relación entre ellos. Además, dentro de un patrón de SRS en gran escala, también encontramos interacción laboral del tipo planteado por Sabatini, entre personas de distintas áreas de la ciudad, y no por eso planteamos la existencia de integración social.

La teoría de la superposición de lógicas espaciales de Castells (1998) cumple el objetivo, en el contexto de la SRS, de evidenciar la complejidad de la relación entre la dimensión geográfica y la social en el actual contexto. Y al hacer patente la pérdida de importancia de la contigüidad física como soporte de las relaciones sociales, resalta la necesidad de estudiar esta compleja relación, ya que lo que antes parecía obvio ya no lo es más. La interacción social no está asegurada por la mera contigüidad o cercanía en el espacio del lugar, menos aún la integración. La superposición de lógicas espaciales genera nuevas formas de segregación espacial, pudiendo ser extremadamente distinta la experiencia de vivir en un mismo lugar, en una misma comuna, para una familia con acceso a la lógica espacial de los flujos que para una que se queda anclada en la del lugar. Lo anterior es corroborado y ejemplificado por los casos en que se ha reducido efectivamente la escala geográfica de SRS, como Peñalolén. 


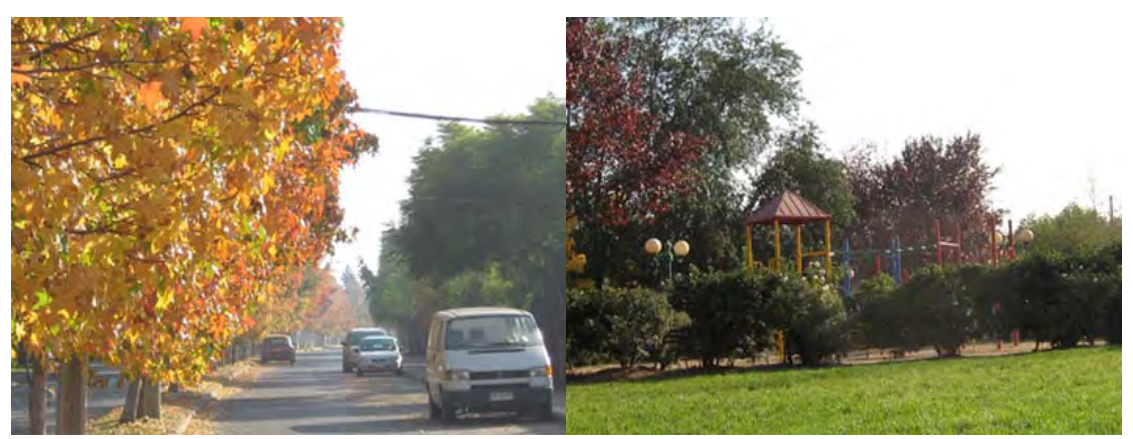

IMAGEN 7. Calles y áreas verdes-recreativas en El Olmo (fotos propias, mayo de 2008).

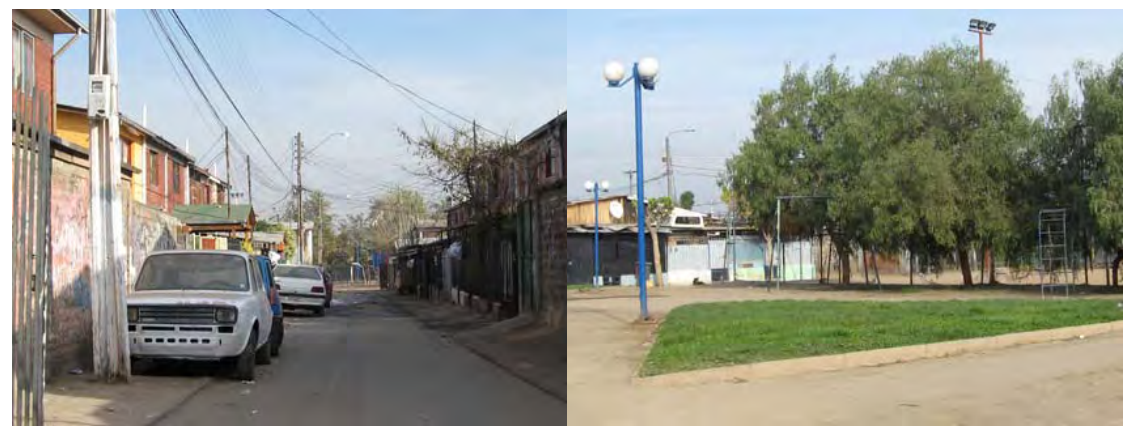

IMAGEN 8. Calles y áreas verdes-recreativas en El Parral (fotos propias, mayo de 2008).

La segregación residencial se observa en relación a sus efectos segregativos en otros ámbitos no-residenciales, como la educación, salud y recreación. Si observamos que coordenadas geográficas de asentamiento residencial muy cercanas generan accesos diversos y contrastantes a estos otros ámbitos, ello quiere decir que no hay una relación directa entre ubicación y acceso, por lo tanto tampoco la hay entre cercanía física e integración social.

Bajo estas condiciones, se hace necesario crear y proponer una definición de la segregación socioeconómica que contemple las relaciones entre los patrones residenciales, el uso y acceso diferenciado a los actuales espacios y servicios, y las interacciones sociales que ellos permiten, impiden, refuerzan o dificultan, abarcando ambas dimensiones, geográfica y social, bajo la convicción de que no tiene sentido estudiar una sin tomar en cuenta los efectos y causas que tiene en la otra. Así, propongo que segregación residencial socioeconómica puede definirse como la situación en la que el patrón bajo el cual se distribuyen, construyen, adquieren e instalan las viviendas de los distintos grupos socioeconómicos en su entorno, genera, expresa o refuerza diferenciación, distancia y mutua exclusión entre estos, obstaculizando su interacción y la integración socioeconómica de los más desfavorecidos. 
Las dimensiones geográfica y social son parte constitutiva de esta definición, según la cual la SRS puede describirse como la interacción entre la dimensión geográfica y la social. Por lo tanto, como ya se ha sugerido, en cuanto a criterios geográficos, no sólo debe tomarse en cuenta la distancia cuantitativa y heterogeneidad relativa, sino también la forma concreta de instalación de las viviendas en el entorno, su materialidad, los límites físicos que se imponen, accesibilidad/inaccesibilidad, la armonía de los diseños en relación a los conjuntos habitacionales que les rodean, adaptación al entorno o modificación de éste, etcétera. En cuanto a criterios sociológicos, debe tomarse en cuenta la existencia/inexistencia de espacios e instancias públicos de encuentro y las interacciones observadas en ellos, servicios básicos y secundarios e infraestructuras compartidas (que realmente sean utilizados y compartidos por los diversos grupos coexistentes, no sólo nominalmente, es decir no sólo que puedan acceder sino que efectivamente accedan a los mismos servicios, espacios e infraestructuras), beneficios y perjuicios de la cercanía a grupos de distinto nivel socioeconómico, la percepción que unos tienen de otros, las actividades que cada uno realiza dentro y fuera de la comuna o nivel de referencia, y las actividades de un grupo que tienen como referente al otro (ya sea prestaciones de servicios remunerados o voluntarios, manifestaciones en contra o a favor del otro, etcétera).

Todo lo anterior se plantea como comparación entre un grupo y otro. Esto no sólo tiene sentido en el caso de la SRS en escala reducida, también en el caso de la gran escala, señalando un nivel de agregación mayor, definiendo la situación de cierto grupo o área en relación al resto de la sociedad o ciudad. Como Rodríguez ha enfatizado, es de gran importancia definir la escala de SRS en cada caso analizado. Esto debe ser un primer paso en la definición de la situación estudiada, pero inmediata o paralelamente debe generarse la comparación en los términos planteados, dependiendo el grupo de referencia del nivel o escala que se ha determinado.

En el fondo del asunto, la unidad de referencia adecuada para un análisis de la segregación residencial socioeconómica como fenómeno dentro de toda una sociedad, es la que contemple o al menos represente a todos los habitantes, sujetos o situaciones de esa sociedad que interactúan entre sí de una u otra manera. Se trata de analizar la forma en que se distribuyen en la ciudad las familias de quienes distribuyen los alimentos, quienes los venden, quienes se llevan las ganancias, quienes los preparan, quienes cuida a los niños, quienes barren las calles, manejan las micros, cargan el 
combustible, dan las noticias, hacen funcionar las telecomunicaciones, arreglan los jardines, reparten los diarios, construyen los edificios, diseñan los edificios, importan productos de tecnología, los venden... etcétera. La importancia del análisis de la SRS reside en evaluar su relación con este contexto general, lo cual no quiere decir que todos los estudios deban tomar al conjunto de la ciudad, pero aunque se analice un caso particular y acotado a un área determinada, su relevancia, impacto y significación tienen sentido en relación al conjunto.

Para finalizar, recalco una vez más la importancia de entender la SRS en sentido geográfico en estrecha relación con el sentido social. Si se acortan las distancias físicas, pero a una niña le da vergüenza vivir donde vive porque la rodea gente de otra categoría social, y su familia, la educación y los medios de comunicación le han enseñado que esa gente es inferior o superior, no podemos hablar de un cambio cualitativo y estructural en las relaciones sociales e instancias de encuentro entre grupos socioeconómicos diferentes, producto de esa menor distancia geográfica.

\section{Referencias bibliográficas}

Amándola, Giandomenico (2000). La Ciudad Postmoderna. Madrid: Celeste Ediciones.

Castells, Manuel (1998). La Era de la Información, tomo 1. Alianza Editorial.

Elgueta, Alejandra (2006). Gran Santiago: transformación del patrón espacial de localización del sector residencial de la elite. Tesis de grado no publicada. Departamento de Geografía, Universidad de Chile.

Ramos, Marcela y Guzmán de Luigi, Juan (2000). La Guerra y la Paz Ciudadana. Santiago: LOM Ediciones.

Revista Vivienda y Decoración, 2008. El Mercurio, sábado 29 de marzo de 2008.

Rodríguez, Alfredo (2001). Segregación residencial socioeconómica: ¿qué es?, ¿cómo se mide?, ¿qué está pasando?, ¿importa? Santiago: CEPAL, Naciones Unidas.

Sabatini, Francisco (2000). Reforma de los mercados de suelo en Santiago, Chile: efectos sobre los precios de la tierra y la segregación residencial. EURE. Ed. Electrónica 26. En http://www.scielo.cl/scielo.php?script=sci arttext\&pid=S025071612000007700003\&lng=es\&nrm=iso . Accedido en marzo de 2008.

Sabatini, Francisco; Cáceres, Gonzalo, y Cerda, Jorge (2001). Segregación residencial en las principales ciudades chilenas: tendencias de las tres últimas décadas y posibles cursos de acción. EURE. Ed. Electrónica $27 . \quad$ En http://www.scielo.cl/scielo.php?script=sci arttext\&pid=S025. Accedido en marzo de 2008.

Sabatini, Francisco y Cáceres, Gonzalo (2004). Los barrios cerrados y la ruptura del patrón tradicional de segregación. En Barrios Cerrados en Santiago de Chile: entre la exclusión y la integración residencial. Gonzalo Cáceres y Francisco Sabatini, editores. Santiago, Lincoln Institute of land policy y Pontificia Universidad Católica de Chile.

Thuillier, Guy (2005). El impacto socio-espacial de las urbanizaciones cerradas: el caso de la Región Metropolitana de Buenos Aires. EURE. Ed. Electrónica 31. En http://www.scielo.cl/scielo.php?script=sci arttext\&pid=S0250$\underline{71612005009300001 \& \operatorname{lng}=e s \& n r m=i s o .}$ Accedido en marzo de 2008. 